\title{
The Operating Agreement
}

By Joseph A. Boissé

ACRL Past President and JoAn S. Segal

ACRL Executive Director

\section{Commentary on the new "Policies of the American Library Association in Relation to Its Divisions."}

ver the fifty years since the establishment of ALA's first divisions, the relationship between them and ALA has undergone many transitions as economic and political forces have driven the Association to reevaluate the financial and governance aspects of its organization. After the "Dues Transition Document" of 1976 established the principle that divisions must be responsible for generating the revenue needed to pay their staff salaries and benefits and to operate their program activities, an "Operating Agreement," adopted in 1982, defined more specifically how financial responsibilities would be allocated.

The Agreement wisely specified that it should be re-examined in five years. In the fall of 1984, the ALA Committee on Program Evaluation and Support (COPES) began a process of examining the 1982 Agreement, considering its strengths and weaknesses, and preparing a more carefully crafted document to guide the ALA/division relationship.

During the past several years, a great deal of energy has been expended by a large number of individuals on the development of a new Operating Agreement. News items have appeared in both American Libraries and C \& RL News. Any member who has attended either an Annual Conference or Midwinter Meeting has undoubtedly been made aware of the discussions and negotiations which have been going on. Even with all that, however, most members of ALA and its divisions think of only one thing when the Operating Agreement comes to mind: how much overhead will the divisions have to pay?

This is an unfortunate circumstance. The Operating Agreement is much more than an agreement concerning how much of the indirect costs incurred by the divisions will be charged back to them. The Agreement attempts to recognize the symbiotic relationship that exists between ALA and its divisions. It recognizes that that relationship is very complex. It identifies organizational values and it does much more.

The purpose of this article is to examine the entire Operating Agreement. The authors have devoted hundreds of hours over time to developing the Agreement. Working on the assumption that an informed membership is a responsible membership, we will examine the process followed and will take each section of the final version, which was approved by the ALA Council at the Dallas Conference, and explain it.

\section{The process}

Relatively slow progress was made after the COPES asked division staff to work on a new agreement, but by the fall of 1986 , the Preamble and the structure for the recently-approved document were complete and the new document was much clearer in form and content than its prede- 
cessor, at least partly due to the experience gained in working with the 1982 document. During this period, ALA leaders became particularly aware of growing indirect costs and sought ways to control them. The allocation to divisions of a larger share of their indirect costs became a matter of serious concern. By the New Orleans Conference in 1988, this aspect of the Agreement took on increased importance and became the dominant issue for discussion. Seeking to establish unequivocally the economic and programmatic importance of divisions to ALA and to ground the new Agreement in a firm philosophical foundation, division and ALA leaders revisited the Preamble and drew up the values statements in the fall of 1988 .

A meeting of representatives from each division, the ALA Executive Board and the COPES, plus division and ALA staff, was held in Lisle, Illinois, in November, giving rise to the epithet "The Lisle 37," and exhortations to "Pass the Operating Agreement and Free the Lisle 37." The meeting achieved several key agreements, chief among them the adoption of the format of the December 1986 document and tentative acceptance of a funding philosophy based on membership dues covering "basic" services (defined in the document) with fees or other sources covering the full cost (including overhead) of "non-basic" activities. Over the next months, there followed a flurry of activity creating models for estimating the financial impact on divisions, individually and collectively, and on ALA. Heated discussions surrounded this activity.

At the Midwinter Meeting in Washington in January 1989, division boards discussed the Agreement and division representatives caucused, but no formal discussions took place. Key meetings occurred in March, when representatives of the COPES met with division staff representatives, and in April, when division representatives held a fruitful and harmonious caucus leading to the suggestion of several significant compromises in a proposal to the COPES. Although these were not accepted, they led to further discussions and pointed in the direction of the version finally reached. Just before the Dallas Conference, new objections were raised by the COPES which were only resolved at the Annual Conference itself. It is unfortunate that the very last stages of preparing the Agreement were acrimonious; the final version reached has much to commend it.

It begins with a Preamble and Statement of Values. Following a set of definitions, it sets forth much more clearly than the previous agreement what the financial and governance responsibilities are on each side of the relationship: what ALA provides free of charge, exactly what divisions pay for, and on what basis.

As the Dallas meeting approached and a final snag occurred in the process, few Association members realized that the argument resolved there centered around one sentence in a 19-page, carefully constructed policy designed to guide relations among ALA and its divisions for years to come.

\section{Preamble}

The Preamble is a beautiful statement of the simplicity and complexity of an association with inextricably related parts. ALA is pictured as unique in its structure, with unity of governance and legal existence, but serving as a home for eleven divisions, each with its own responsibilities, goals, personnel, revenue objectives, and Board of Directors.

It describes the divisions' responsibility to their members and the fact that the service they provide serves ALA as a whole. It points out that ALA, by providing space and services to divisions, gives tangible evidence that it recognizes divisions' importance. The relationship is seen as dynamic and collaborative, with a mutuality in relationships, and the potential for cooperative work among units.

The Preamble suggests that the new set of policies must recognize the contributions we make to one another and the joint nature of the decisionmaking process. Finally, it states, "this document is designed to continue a cooperative framework in which the inevitable questions of organizational relationships can be addressed and resolved."

\section{Current Organizational Values of ALA}

Through a careful analysis of existing ALA documents, the following organizational values were identified: 1) Unity, 2) Diversity, 3) Authority, 4) Autonomy, and 5) Collaboration/Cooperation.

Why are these organizational values included in the Operating Agreement? Because they recognize the unique nature of the relationship between ALA and its divisions and because they establish what one might call "ground rules." In the deliberations which resulted in the Operating Agreement, the parties were guided by these values.

The values recognize that ALA is one organization and that uniform policies and procedures apply in administrative, personnel, and financial areas. It also recognizes that the divisions provide a mechanism whereby librarians with very diverse interests can become involved in the work of ALA. The statement reminds us that ALA has delegated to each division responsibility to represent the whole in certain specified areas. Divisions enjoy a certain amount of autonomy in the way they do their work and carry out their programs. Finally, ALA and its divisions work together and make use of each other's strengths, thereby ensuring that the whole is greater than any one of its parts. 


\section{Purpose, Scope, Implementation, Review Process, \& Definitions}

This section of the document explains what the Association seeks to achieve with the Operating Agreement. It further explains the annual review process which will now be in place and defines various terms referred to in the document.

\section{Use of ALA Services}

This section lists services provided by ALA which divisions are required to use. This includes telephone, personnel services, membership services, insurance, purchasing, fiscal services, legal counsel, archives, and ALA-owned or leased space.

\section{Financial}

A. Dues. This paragraph recognizes every division's right to establish dues and to establish membership perquisites for its members.

B. Council Actions with Fiscal Implications. When ALA's Council assigns a task to a division, COPES and the division board will review the assignment and report back to Council. Council may then recommend a budgetary adjustment for the division. In essence, this statement recognizes that it costs a division money to carry out such assignments and that Council must acknowledge this.

C. Services and Charges. This is a veryimportant part of the Operating Agreement and one around which some of the most intensive discussion took place. The first section enumerates those items which ALA provides to the divisions at no direct charge. For instance, office space, certain telephone services, basic furniture requirements, personnel services, storage and warehouse space, staff travel costs, and per diem for the two major ALA meetings each year, equipment for meetings and programs at conference, various services provided by the Fiscal Services Department, the Washington Office, the various program offices and the Headquarters Library.

The second section identifies the services for which ALA charges divisions the actual costs. This includes, among other things: certain telephone services such as long distance calls, specialized data processing, printing and duplication, and postage for special mailings. It explains how and on what activities overhead charges will be paid by the divisions. The overhead rate will be set annually. On income from divisional conferences, workshops, institutes, etc., the divisions will pay $100 \%$ of the ALA indirect cost rate. However, the imposition of those charges will be implemented over a five year period: $1989-90,0 \%$; $1990-91,50 \%$; $1991-92,50 \%$; 1992-93, 75\%; 1993-94, 100\%.
This will give the divisions time to plan and work the costs into their charges for these services. On income from net sales of materials, advertising, subscriptions, and publications, overhead will be assessed at $50 \%$ of the ALA rate. This charge will be implemented in equal annual increments over a five-year period. ACRL will pay the full $50 \%$ related to Choice immediately. The divisions will also pay directly for certain expenses previously considered as indirect ALA costs. These include subscription and order billing services and Central Production Unit services. These charges will be levied beginning in 1990-91.

Expenses incurred for the Division Leadership Enhancement Program and Awards promotion will be shared by ALA and its divisions.

The divisions must assume total financial responsibility for division personnel costs, all division projects unless otherwise specified in the Operating Agreement, the work of committees and sections, and any equipment over which a division wants to have sole control and use.

Lastly, a division may purchase services and/or products from other ALA units and outside agencies, consistent with ALA policy.

D. Fund Balances. The Operating Agreement recognizes that divisions may build fund balances, but states that they will receive no interest on those funds. Some have asked about the rationale behind fund balances. A fund balance allows the organization to proceed from one year to the next without worrying about what will happen if income suddenly takes a plunge. The fund balance is a reserve on which the Association can draw if there is a sudden drop in membership, if a conference proves to be a money-loser, or if some other unexpected problem results in a drastic reduction in projected income or increase in expenses.

E. Endowments. Some divisions have modest endowments. The Operating Agreement encourages divisions to establish and build endowments. It allows divisions to transfer funds from existing balances once they have established a minimum fund balance. The income from such endowments is controlled by the divisional board and is not subject to any overhead costs.

F. Furniture. ALA will provide basic equipment to each regular division staff member. This section recognizes that a division may purchase some of its own equipment and, if it does, it retains total control over that equipment. It also describes the various ways by which equipment may be purchased by divisions.

G. Division Budget Review. Division boards have the responsibility to prepare budgets and financial plans. These are reviewed by ALA management and COPES. The last stage of the review process takes them to the ALA Executive Board for its approval. 
H. Divisions with Small Revenue Bases/Number of Members. Recognizing that certain divisions have a small base of revenue or a small number of members because of their particular specialty, and that divisions are established by Council to carry out specific responsibilities, but that all divisions must have staff and must provide basic services, the Agreement acknowledges that ALA has some obligation to supplement division financial support. This section specifies that such support is to be part of a regular planning process and describes how the exact amount of the ALA assistance would be determined. Each division must generate at least $50 \%$ of the funding required to provide basic services. If it is unable to do so for two consecutive years, the Executive Board will consider its status as a division and refer action to Council. Careful attention was given to the question of non-dues revenue. ALA General Funds will not be used to offset expenses associated with generating such revenue, but divisions may retain the net revenue.

I-J. Association Finances and Other. These sections state that ALA will keep divisions informed about its own general financial condition and involve them about matters with potential impact on divisions, collectively or individually. They promise effective credit and collection policies, while establishing division responsibility for their bad debts and unrelated business income tax.

\section{Publishing Activities}

This section establishes the ways a division may publish materials: through ALA Publishing, on its own, or through an outside publisher. It states that a division must offer material prepared for other than its own publication to ALA Publishing for first consideration, but may accept or reject the ALA offer. It also points out that divisions may purchase services, such as production and distribution or marketing, from appropriate ALA Publishing units. It acknowledges division rights to negotiate royalties for its publications through an "Intramural Agreement of Publishing Responsibility." ALA is given sole right to record and market tapes of conference programs, for which divisions receive royalties. Divisions may record and market tapes of other activities.

\section{Personnel}

All division staff members are ALA employees and subject to ALA personnel policies. Divisions must generate the revenue to pay their staff salaries and benefits. Division Executive Directors hold senior professional positions at ALA and have appropriate and reasonable ALA responsibilities; they also meet together regularly to communicate, cooperate, and coordinate division activities. ALA
Personnel policies determine the grade level of positions; division Executive Directors and boards determine appropriate staffing patterns, in consultation with the ALA Executive Director. Division directors' recruitment, appointment, and termination involve consultation by the division board and the ALA Executive Director. Performance review of division directors is an annual process that uses a set of goals agreed upon by the director, the division board, and the ALA Deputy Director. Selection, evaluation, and termination of other division staff is under the authority of the division director, consistent with ALA Personnel policies and procedures.

\section{VIII-X. Division National Conferences, Preconferences, and Related Activities; Annual Conference and Midwinter Meeting; and Special Projects of Divisions}

These sections recognize a division's ability to engage in various activities to enhance its programming and services to members. They specify the conditions which must be followed in these areas. With respect to Annual Conferences and Midwinter Meetings, the document specifies how ALA will assist in making activities at those sessions possible.

\section{Planning}

Divisions have autonomy in planning, but are expected to develop and implement a planning process that includes both multi-year program and financial plans. They are given responsibility to assist and inform the ALA Planning Committee by sharing these plans on a regular basis and by contributing to the Action Inventory.

\section{Conclusion}

As we stated at the outset, ALA is an enormously complex organization. If the relationship between the Association and its divisions is to remain harmonious, it is imperative to have clearly enunciated policies and procedures which govern the relationship and the interaction which takes place. Earlier Operating Agreements began that process. The current document goes considerably further than its predecessors in clarifying the relationship and in explaining the rules which both players will follow.

The development of this Operating Agreement involved many of the Association's members. It represents the bringing together of diverse threads into a solid chain which links ALA and its divisions and allows them to function harmoniously and effectively as they strive to achieve their goals. 


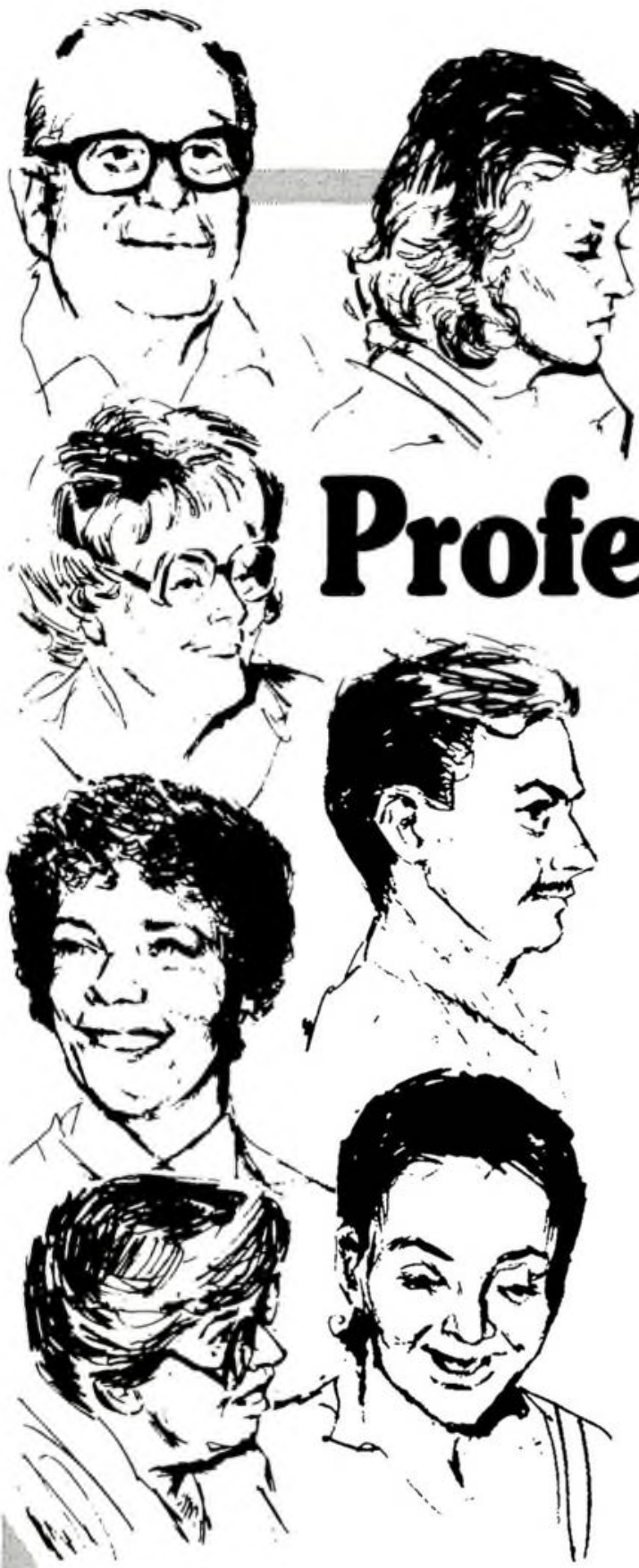

\section{We Are sionals}

We at EBS are dedicated to providing libraries with the fastest service, the best discounts, but above all, the accuracy a library demands.

With all this in your favor you owe it to yourself to try us...

\section{IIIIIIIIIIII 1949-1989/40 Yeans of Excellence}

